\title{
Comparison of COADS Release 1a Winds with Instrumental Measurements in the Northwest Atlantic
}

\author{
SERGEY K. GuleV \\ P. Shirshov Institute of Oceanology, Moscow, Russia and \\ Institut für Meereskunde, Kiel, Germany
}

(Manuscript received 6 October 1995, in final form 18 February 1998)

\begin{abstract}
The reliability of the Comprehensive Ocean-Atmosphere Dataset (COADS) Release 1a $2^{\circ}$ monthly winds is tested by comparing it with instrumental measurements in the northwest Atlantic from 1981 to 1991. The instrumental dataset contains anemometer measurements of a very high homogeneity and quality, which were taken by six research sister ships with known anemometer heights in the northwest Atlantic. Special data processing was made with instrumental samples to provide compatibility with the COADS winds. Comparison shows overestimation of the COADS winds in the low ranges and underestimation of the strong and moderate winds. Application of the alternative equivalent Beaufort scales does not remove this bias and makes it even more pronounced. Thus, the conclusion is made that the disagreement obtained results primarily from the uncertainties of anemometer measurements in COADS, especially from the incorrect evaluation of the true wind. Instrumental data also do not indicate significant long-term interannual changes, which are pronounced in the COADS dataset for the 1980s. Some regional features of the comparison are discussed.
\end{abstract}

\section{Introduction}

There has been considerable debate about the reliability of the Comprehensive Ocean-Atmosphere Dataset (COADS) winds - particularly the long-term wind speed trends (Ramage 1984; Peterson and Hasse 1987; Cardone et al. 1990; Lindau et al. 1990; Isemer and Hasse 1991; Ward 1992; Ward and Hoskins 1996; Bigg 1993; Isemer 1994, 1995), ranging from 0.1 to $0.5 \mathrm{~m}$ $\mathrm{s}^{-1}$ per decade with local maxima in the Tropics and in the Norwegian Sea (Isemer 1995). Change with time of the relative role of anemometer measurements is considered as one of the possible reasons of the unrealistically high COADS wind trends, although there is a number of other reasons that are still poorly understood. Isemer (1995) made a comprehensive comparison of the COADS winds with the surface and upper-air measurements on the ocean weather stations (OWSs) from the late 1940s to early 1970s and found that COADS wind trends in the North Atlantic are in a disagreement with those taken from the OWSs and should be at least significantly reduced after the accurate application of Beau-

Corresponding author address: Sergey Gulev, P. Shirshov Institute of Oceanology, RAS, 36 Nakhimovski Ave., 23 Krasikova str., 117218 Moscow, Russia

E-mail: gul@gulev.sio.rssi.ru fort scale and careful consideration of individual sampling statistics. Although COADS Release 2 covering the period 1820-97 will be available in the year 2000 (Woodruff et al. 1998), COADS Release 1a data for 1980-93 are already widely used by climatologists (Woodruff et al. 1993). Release 1a indicates an even more pronounced increase of scalar wind speed (Diaz et al. 1995). Wu and Li (1995) obtained significant upward trends in the North Atlantic evaporation during 1979-87 using COADS Release 1a. Application of the Cardone et al. (1990) correction reduces trends but does not reject them. Gulev (1995) found an unrealistic increase of the North Atlantic sea-air fluxes computed from COADS Release 1a for the 1980s. The recently published da Silva et al. (1994) climatology also indicates primarily positive anomalies of the wind speed in the North Atlantic in the 1980s.

Figure 1a shows differences in the wind speed between the decades 1970-79 and 1980-89, as computed from the COADS Monthly Summary Trimmed Groups (MSTG) data. Nearly the entire North Atlantic indicates positive trends between the 1970s and 1980s, ranging from 0.2 to $1.0 \mathrm{~m} \mathrm{~s}^{-1}$ per decade. The most pronounced upward changes are located along a major shipping route in the midlatitudes, where the wind speeds are higher than $0.5 \mathrm{~m} \mathrm{~s}^{-1}$. Figure $1 \mathrm{~b}$ shows a long-term series of the scalar wind speed averaged over the area $40^{\circ}-46^{\circ} \mathrm{N}$, $38^{\circ}-46^{\circ} \mathrm{W}$ in the northwest Atlantic, which gives an upward trend of $0.63 \mathrm{~m} \mathrm{~s}^{-1}$ per decade during the 1970s 
(A)

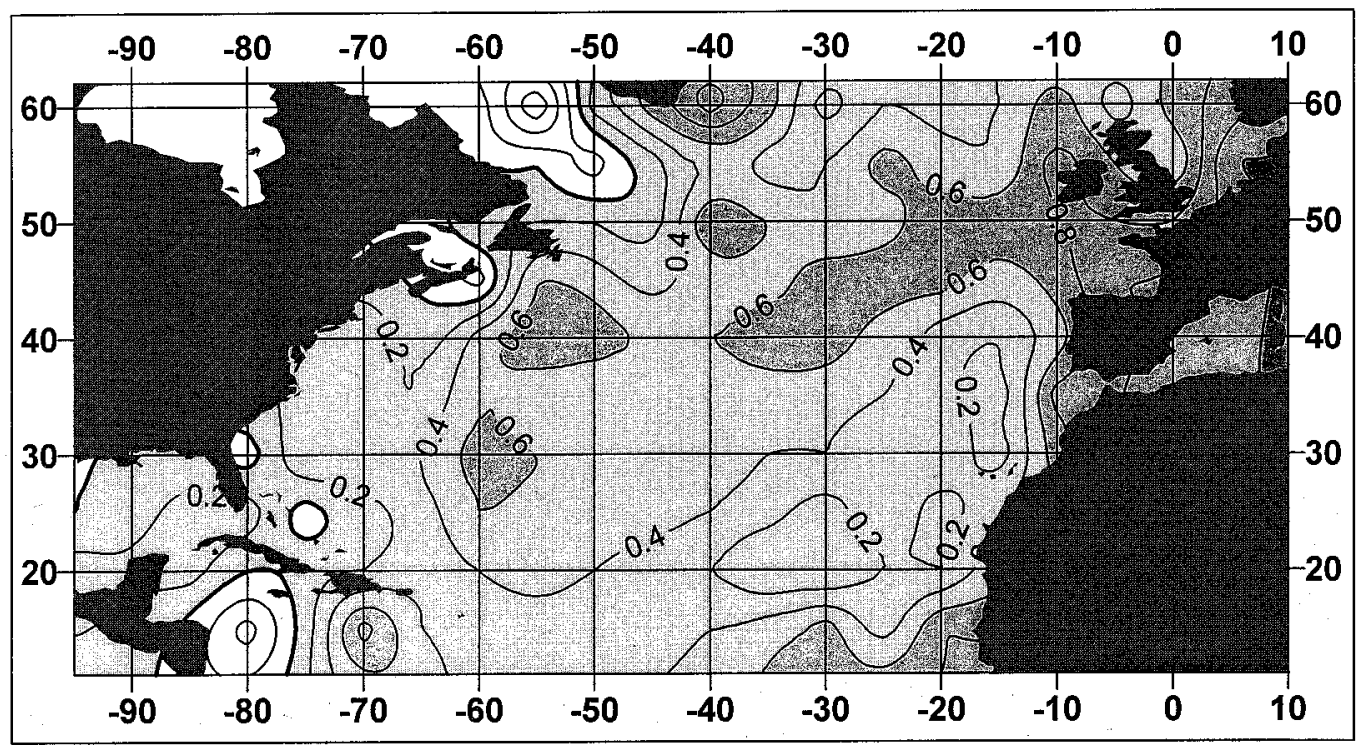

(B)

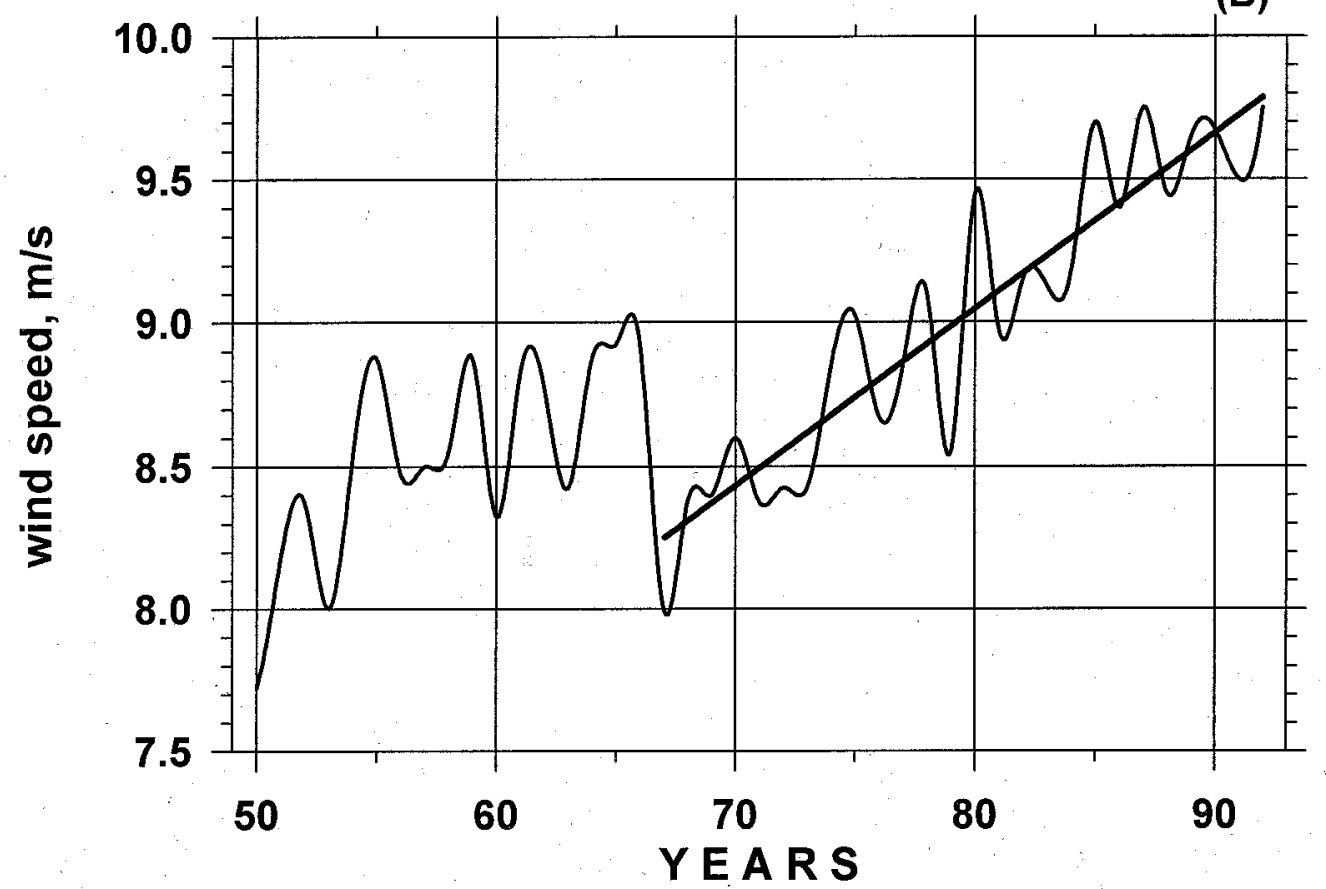

FIG. 1. (a) Differences in scalar wind speed $\left(\mathrm{m} \mathrm{s}^{-1}\right)$ between the 1970s and 1980s computed from COADS Release $1 \mathrm{a}$, and (b) long-term series of COADS wind speed from 1950 to 1992 averaged over the area $40^{\circ}-46^{\circ} \mathrm{N}, 38^{\circ}-46^{\circ} \mathrm{W}$ in the northwest Atlantic. The bold line indicates long-term linear trend over the 1970s and 1980s.

and 1980s. To test the COADS Release 1a winds in 1980 s it is desirable to use alternative instrumental measurements. However, measurements at most OWSs were stopped in mid-1970s. Observations at OWS C were continued until 1990, but the homogeneity of record is questionable due to occupation of the OWS C by Soviet research vessels starting in July 1975 (Isemer 1994). The recently completed Voluntary Ship Observing Programme in the North Atlantic (VSOP-NA) (Kent et al. 1993) provides data from voluntary observing ships 
(VOSs) along a number of ship tracks in the North Atlantic midlatitudes. However, the VSOP-NA data were gathered only from 1989 to 1991 and contain a number typical for the VOS data inhomogeneities, which are documented by Kent and Taylor (1991) and Kent et al. (1991). Thus, COADS Release 1a needs other sets of instrument measurements for the intercomparison. This is extremely important in view of the high interest of climate researchers in the new COADS releases, especially in the North Atlantic area. This work attempts to use instrumental data of a very high quality for the validation of COADS Release 1a winds in the northwest Atlantic.

\section{Data}

COADS Release 1a is used in this study in form of MSTG, which contain monthly means and intramonthly standard deviations of basic meteorological variables for $2^{\circ} \times 2^{\circ}$ boxes for $1980-93$ (Woodruff et al. 1993). This product was computed on the basis of individual observations by the COADS community in the same manner as the earlier COADS Release 1 for 1854-1979 (Slutz et al. 1985) and is widely used by climate researchers. For a more detailed comparison of some parameters we have also used individual meteorological observations from the COADS Release 1a in the northwest Atlantic, known as long marine reports (LMRs). Release 1a contains a smaller number of reports (5\%$25 \%$ less during the 1980s) than the Release 1 has for the earlier decades. At the same time, in the northwest Atlantic the drop of the number of reports is not so pronounced, and for some boxes there is even a tendency of increasing number of samples.

For the comparison with instrumental observations, we used the data collected by the research vessels $(\mathrm{R} / \mathrm{Vs})$ in the northwest Atlantic within a 10-yr period 1981-91 under the Energetically Active Zones of the Ocean and Climate Variability program (SECTIONS) (Gulev 1994). Figure 2a shows spatial distribution of samples in this dataset. All data were collected by professional meteorologists on board the six sister ships [the same ships that operated at OWS C from 1975 to 1990 (Isemer 1994)]. The ships were $98 \mathrm{~m}$ in length (Fig. 3) and traveled at 6-15 kt. Wind data were gathered solely from fixed anemometer measurements. Anemometer level varied from 26.7 to $27.5 \mathrm{~m}$. Cup anemometers (model GM48) were used on all six ships. Observational sensor accuracy of GM48 varies from $0.4 \mathrm{~m} \mathrm{~s}^{-1}$ for small and moderate winds to $0.8 \mathrm{~m} \mathrm{~s}^{-1}$ for strong winds. Two fixed anemometers were well exposed at the mast on the top deck (Fig. 3) to reduce the distortion of the wind measurements by the ship superstructure (Kahma and Lepparanta 1981; Blanc 1986). The height of anemometers above the top deck is from 14.7 to $15.2 \mathrm{~m}$ (Fig. 3). Thus, the ratio between wind speed sensor altitude and ship superstructure height $\left(\mathbf{z}_{u} / S_{H}\right)$ (Blanc 1986) for these two anemometers is from 2.1 to 2.25 .
An approximate estimate of the exposure index (Kent and Taylor 1991) for these two anemometers is nine, at least for the relative winds from ahead, the starboard beam, and port beam. The third anemometer was at the astern signal mast, where $\mathbf{z}_{u} / S_{H}=1.7$, and had an exposure index of nine for relative winds from astern, the starboard beam, and port beam. This anemometer was used for the clarification of cases when the two main anemometers gave significant differences between each other. The fourth anemometer at the meteorological tower at the ship's bow was not regularly used. GM48 was successfully used for both true and relative wind measurements. Note that about $60 \%$ of wind measurements were taken during either hydrographic or meteorological stations when the ships were stationary. When the ships were traveling, the calculation of the true wind from the relative wind measured by the same anemometers was taken on board by professional meteorologists using the ship's velocity and course. The total number of cruises used is 91 , the total number of reports is 47535 , and the temporal resolution is from 1 to $3 \mathrm{~h}$. The most valuable data were sampled during NEUFOUEX-88 and ATLANTEX-90 (Gulev 1994) experiments, which were designed to study air-sea interaction using ships, balloons, buoys, and moorings in the Newfoundland basin during November 1987-April 1988 and December 1989-May 1990, respectively. Although the measurement program was designed primarily for the region $40^{\circ}-48^{\circ} \mathrm{N}, 40^{\circ}-48^{\circ} \mathrm{W}$, meteorological observations were sampled within the larger area. We have selected from the COADS MSTG only those $2^{\circ}$ boxes for only those months where and when the $\mathrm{R} / \mathrm{V}$ data were available. Figure $2 \mathrm{~b}$ shows the ratio between the number of observations in the COADS (for only these months) and the number of the R/V reports for 1981-91. Although the number of COADS reports is usually from 2 to 10 times higher than the $\mathrm{R} / \mathrm{V}$ reports, in some boxes located primarily in the region $36^{\circ}-50^{\circ} \mathrm{N}, 36^{\circ}-50^{\circ} \mathrm{W}$, the number of the COADS and R/V reports is comparable. Figures $4 \mathrm{a}, \mathrm{b}$ compares the seasonal progression in the number of instrumental measurements and COADS reports. Again, only those months and $2^{\circ}$ boxes that provide the $\mathrm{R} / \mathrm{V}$ data were taken into account. Most of instrumental data were collected during winter and spring, when the number of instrumental observations is from $35 \%$ to $70 \%$ of the COADS reports. Interannual variability (Fig. 4b) shows that for 1988 and 1990 the number of observations in the R/V and COADS collection are nearly equal. For the other years the $\mathrm{R} / \mathrm{V}$ data is three to six times smaller than the COADS data. Using COADS LMR, we checked (by matching the ship sign, coordinates, and the time of observations) how many of the SECTIONS data were reported via the global telecommunication system and included into the COADS Release 1a. Figures 4a,b shows that the data match constitutes approximately $25 \%$ of the SECTIONS data available. At the same time, this ratio can be in fact slightly higher due to possible missing of the call signs 
from some of the SECTIONS reports in the COADS collection.

\section{Results}

\section{a. Climatological and seasonal means}

For the comparison with the COADS Release 1a winds, instrumental data were averaged for individual months into $2^{\circ} \times 2^{\circ}$ boxes, that is, we made the same processing as has been used to create the COADS Release 1a. Since we used the so-called standard version of COADS, we applied $3 \sigma$ data control procedure to our collection of instrumental measurements. Before the averaging, we applied the height correction to the R/V wind measurements in order to fit them to the expected level of the COADS wind measurements. Anemometer height of the R/V measurements varies from 26.7 to $27.5 \mathrm{~m}$. It is difficult to estimate precisely the exact mean height of wind measurements in the COADS MSTG. All visual estimates are considered as taken at the effective height of $10 \mathrm{~m}$, as specified by the World Meteorological Organization (WMO) (WMO 1970). Kent and Taylor (1997) give from 50\% to $80 \%$ as an estimate of the anemometer measurements in the COADS collection in this area for January 1986. Our overall estimate for the 11-yr period is somewhat smaller and gives approximately $38 \%$ with variations from $20 \%$ to $73 \%$. Thus we can apply a 10 -m estimate to roughly $60 \%$ of observations in the COADS Release 1a collection. For the remaining observations (about 40\% of ships with fixed anemometers) Kent and Taylor (1997) report that the height of wind measurements varies from 10 to more than $50 \mathrm{~m}$ in this region. Although there are many relatively small, mostly fishery ships, which operate in this region and carry fixed anemometers, some wind speed records are contributions from Canadian oil towers that are 60-100 m high. VSOP-NA ships traveled in this region (Kent and Taylor 1991) have an average anemometer height of $34 \mathrm{~m}$, which can be taken as typical for the large cargo ships. We can take $20-30 \mathrm{~m}$ as a typical height of a fixed anemometer in this region during the 1980s. Merging this estimate with the 10-m height of Beaufort estimates we obtain an effective average height of about $16 \pm 2 \mathrm{~m}$. Note that even high-quality instrumental observations are not free from the wave-induced errors. Hasse et al. (1978) found double wave heights as an appropriate accuracy range of the height of a "fixed" anemometer. This estimate depends on the ship size and type.

To adjust wind speed measurements at the R/V to different anemometer reference levels (ARLs) and neutral stability we applied to every report in the Liu et al. (1979) scheme with the Large and Pond (1981) neutral coefficient. During summer months, a considerable part of the area is characterized by stable stratification, which also appears in the other seasons during the warm-air outbreaks. Stable stratification can lead to the decou- pling of the surface layer and therefore to the poor height correction. We have selected cases with very stable conditions using the limit $z / L>1$ (Kent and Taylor 1997) and excluded them from our collection. Then we excluded from further analysis all $2^{\circ} \times 2^{\circ}$ boxes that contain more than $4 \%$ of those very stable cases per individual month in order to avoid the biases in theR/V monthly means. This procedure retains only the few boxes that can be used for the period from May to September, and further consideration will be given primarily for winter (January-March) and autumn (October-December). Taking into account an uncertain exact definition of the mean height of wind estimates in the COADS collection, we adjusted R/V wind speed to several ARLs: 25, 20, 15, and $10 \mathrm{~m}$. Height correction to a 15-m ARL reduces anemometer winds somewhat by $1-2 \mathrm{~m} \mathrm{~s}^{-1}$ and the mean $2^{\circ}$ values by approximately 0.6 $\mathrm{m}$, which is in general agreement with Dobson (1981).

Then the original (taken at 27-m height), the adjusted (to four ARLs), and the neutral stability R/V wind measurements were averaged into $2^{\circ} \times 2^{\circ}$ boxes within the area $36^{\circ}-56^{\circ} \mathrm{N}, 36^{\circ}-56^{\circ} \mathrm{W}$ for individual months from 1981 to 1991. Kent et al. (1991) and Kent et al. (1993) did not find any significant differences between the daytime and the nighttime anemometer winds, although the difficulty of estimating the wind speed from sea state in the dark can lead to $0.5-2 \mathrm{~m} \mathrm{~s}^{-1}$ higher visual daytime values in comparison with those taken during the nighttime (Kent at al. 1991; Kent et al. 1993). To ensure that our data do not contain systematic bias between the daytime and nighttime observations, we compared climatologies, computed for the daytime and the nighttime, and found the values to be almost identical. Differences between daytime and nighttime values for both climatological and monthly means are less than $0.1 \mathrm{~m} \mathrm{~s}^{-1}$. For individual months such differences are slightly higher (within the range of $0.3 \mathrm{~m} \mathrm{~s}^{-1}$ ), and do not have systematic character.

To use a two-way regression for the comparison, we have to ensure that the intramonthly total variance (resulting from the naturally synoptic and error variance) is equal to the compared $2^{\circ} \times 2^{\circ}$ values. On the other hand, we have to use only those boxes that contain a sufficient number of observations per month to avoid biases that result from inadequate sampling (Weare and Strub 1981; Legler 1991). Weare and Strub (1981) found 11 observations to be appropriate for unbiased intramonthly averaging. da Silva et al. (1995) used $30 \mathrm{ob-}$ servations per month for a $5^{\circ} \times 5^{\circ}$ box around OWS P. The number of reports for the $2^{\circ} \times 2^{\circ}$ box in the COADS collection varies from several measurements to several hundreds of measurements per individual month, although most boxes during the 1980s contain 30-70 reports per month. In our collection this value is lower and varies from 5 to 45 observations per month. First, we have selected only those $2^{\circ}$ boxes that contain at least $24 \mathrm{R} / \mathrm{V}$ reports per month. Then, for all these data and the corresponding boxes in the COADS data we 

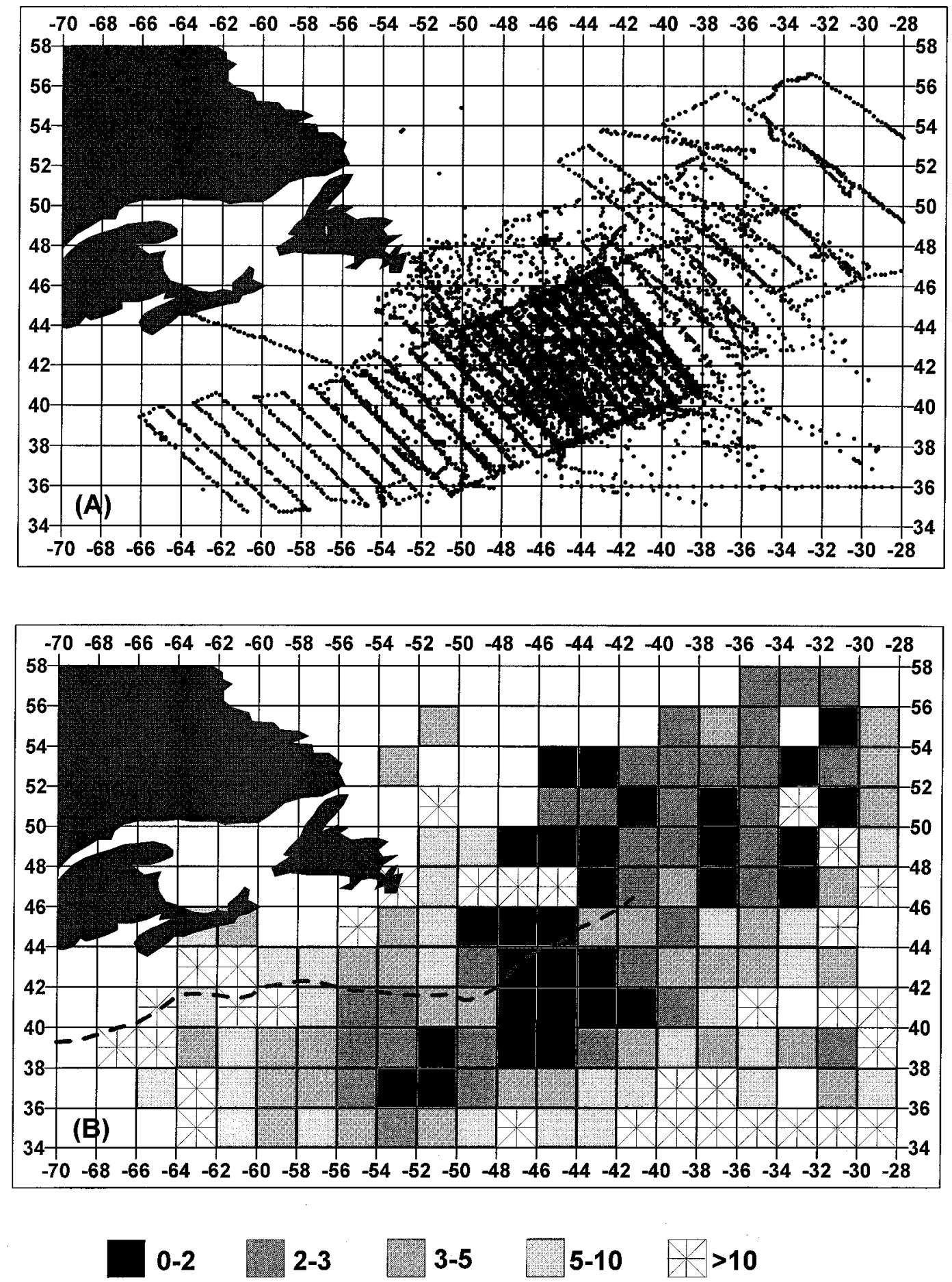

FIG. 2. (a) Spatial distribution of the SECTIONS R/V measurements in the northwest Atlantic and (b) the ratios between the number of COADS reports and RV reports in $2^{\circ}$ boxes. The thick dashed line shows the mean position of the subpolar SST front in the northwest Atlantic.

have applied a $\chi^{2}$ test to select the pairs with the equal intramonthly variances at a $95 \%$ significance level. After the elimination of the boxes with very stable cases and a $\chi^{2}$-test application, 278 pairs of $2^{\circ}$ monthly means were selected for our use. The less powerful $F$ test provides a selection of 313 pairs, although the further results are quite comparable for these two sets. The ratio between mean intramonthly total variance and the mean 


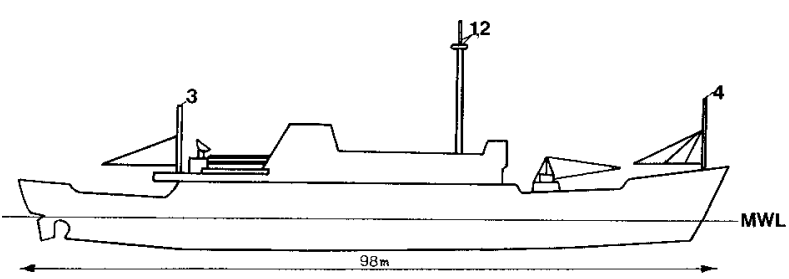

FIG. 3. Schematic drawing of the sister ship that collected instrumental measurements. Numbers indicate the positions of fixed anemometers.

number of observations is practically equal for the $\mathrm{R} / \mathrm{V}$ and COADS data chosen. The selected pairs belong primarily to the area southward of the subpolar sea surface temperature (SST) front (Figure 2b) where very stable cases do not occur. Some test calculations were performed for the lower limits of the monthlyR/V reports. For $n_{\min }<24$ only less than $8 \%$ of cases satisfy the condition of the equal intramonthly variances in the COADS and R/V data, which results from the considerable undersampling of $\mathrm{R} / \mathrm{V}$ reports. Alternatively, when the higher than $n_{\text {min }}=24$ limit is used, we surely have complete sampling but come up with incomplete regional climatology due to a limited total number of boxes that satisfy this limit. We will show later (Table 2) that even a $n_{\min }=24$ limit does not give the possibility to explicitly cover summer and spring seasons.
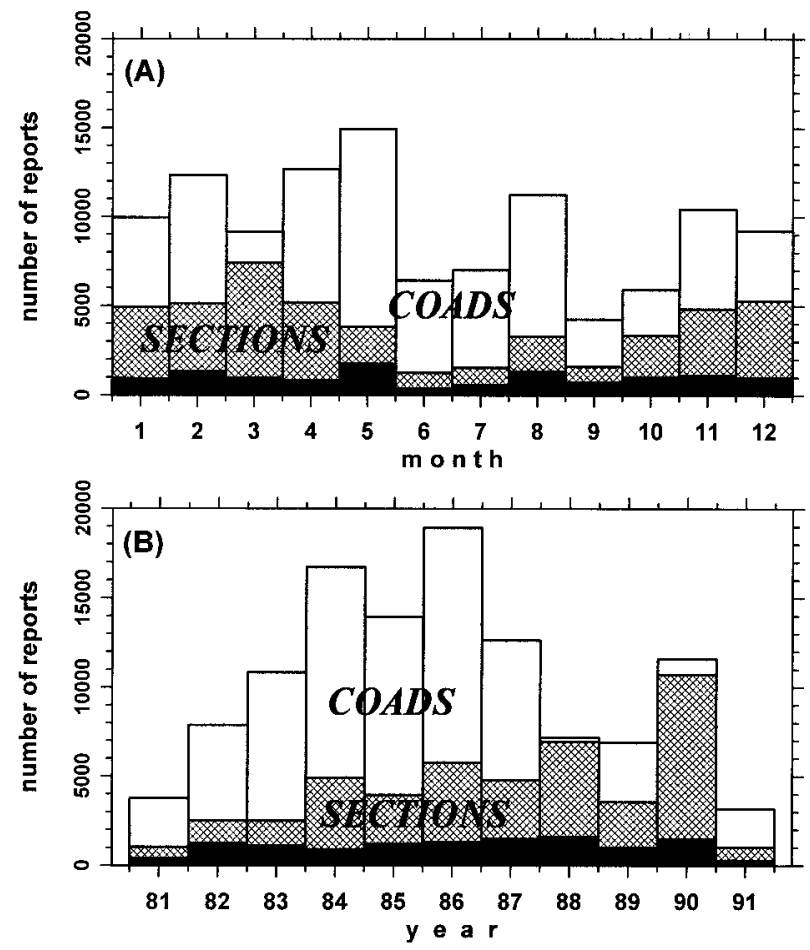

FIG. 4. (a) Seasonal and (b) interannual distribution of the number of observations in COADS Release 1a (gray area), SECTIONS data collection (shaded area), and the $\mathrm{R} / \mathrm{V}$ reports included into the COADS collection (black area) from 1981 to 1991. The bars overlap each other.
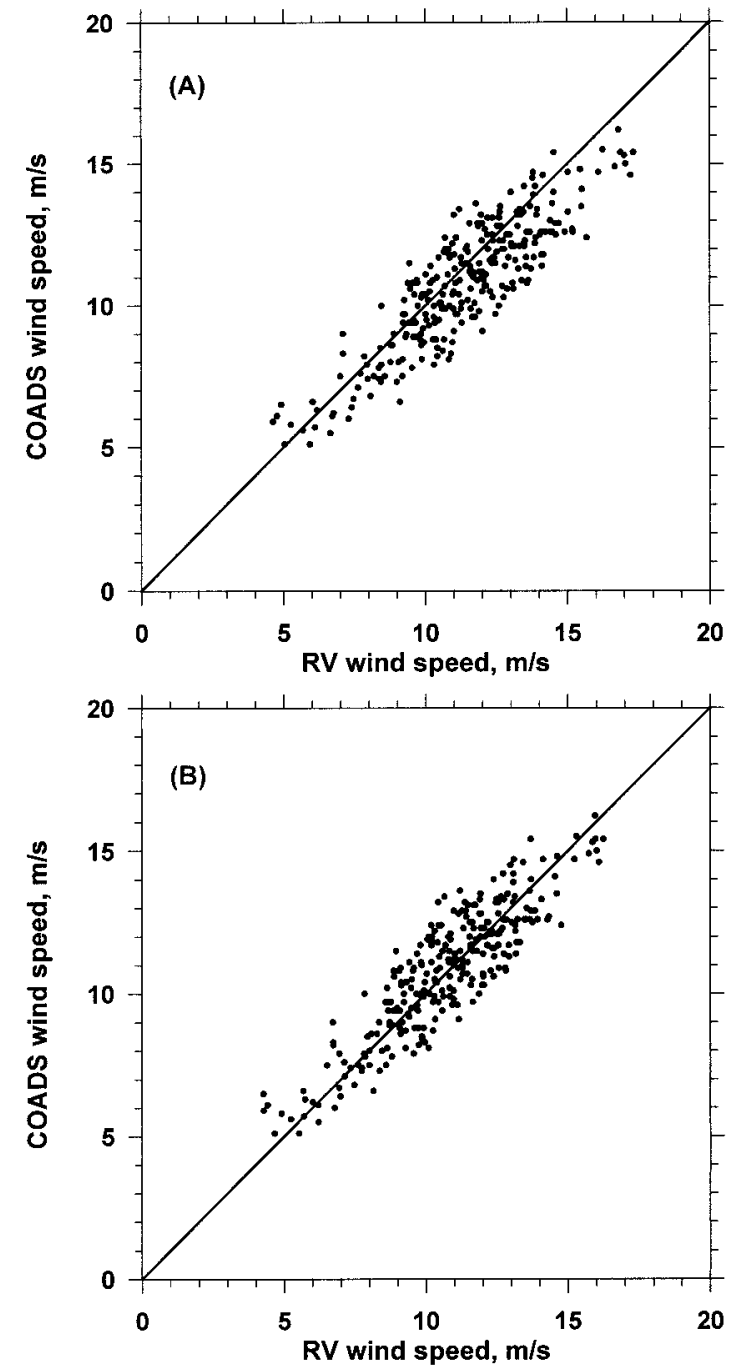

FIG. 5. Scatterplots of the monthly mean $2^{\circ} \mathrm{R} / \mathrm{V}$ and COADS wind speed for (a) ARL $=27 \mathrm{~m}$ and (b) $\mathrm{ARL}=15 \mathrm{~m}$.

Figure 5a shows a scatterplot of the monthly mean $\mathrm{R} / \mathrm{V}$ wind speed and COADS wind speed for the selected $2^{\circ} \times 2^{\circ}$ boxes without height correction. The estimate of a two-way orthogonal regression slope is 0.92 , and the intercept is $0.61 \mathrm{~m} \mathrm{~s}^{-1}$. Systematic shifts appear in both high and low wind speed ranges. Taking into account a systematically higher measured winds in comparison with those estimated from VOS, this value is even smaller than can be expected (Quayle 1980; Kent et al. 1993; Isemer 1995; Kent and Taylor 1997). Thus, using Quayle (1980) to compare OWS and VOS (old WMO code 1100) winds resulted in the highest difference of $2 \mathrm{kt}$ within the range from 0 to $17 \mathrm{~m} \mathrm{~s}^{-1}$, which composed $95 \%$ of his dataset. According to Quayle (1980), the VOS winds are slightly overestimated in the higher ranges and slightly underestimated in the lower ranges. Beaufort estimates compose about $60 \%$ of wind data in this region. Thus, disagreement results from data 
TABLE 1. Regression slopes and intercepts $\left(\mathrm{m} \mathrm{s}^{-1}\right)$ for the pairs of monthly mean COADS and R/V wind speed for different ARLs used for adjustment of $\mathrm{R} / \mathrm{V}$ winds.

\begin{tabular}{ccccc}
\hline \hline ARL & Slope & $\begin{array}{c}\text { Slope } \\
\text { variance }\end{array}$ & Intercept & $\begin{array}{c}\text { Intercept } \\
\text { variance }\end{array}$ \\
\hline 27 & 0.921 & 0.053 & -0.61 & 0.23 \\
25 & 0.928 & 0.056 & -0.58 & 0.23 \\
20 & 0.943 & 0.045 & -0.46 & 0.24 \\
15 & 0.962 & 0.048 & 0.02 & 0.20 \\
10 & 0.984 & 0.043 & 0.57 & 0.21 \\
\hline
\end{tabular}

obtained by Quayle (1980) when compared to the WMO code 1100 (WMO 1970, 1973). These results are explained by Cardone et al. (1990) and Isemer and Hasse (1991). Alternatively, our disagreement (Fig. 5a) indicates lower values for moderate and strong winds. Figure $5 \mathrm{~b}$ shows a scatterplot for the adjusted 15-m ARL, and Table 1 shows how the slope and the intercept change with the decreasing of the ARL from which the $\mathrm{R} / \mathrm{V}$ measurements were adjusted. The regression slope increases with decreasing ARL and becomes close to 1 for $\mathrm{ARL}=10 \mathrm{~m}$. Intercept reasonably increases and changes the sign (COADS winds are higher) for ARL $=15 \mathrm{~m}$, which is probably the most reliable estimate of the effective mean height of wind measurements in COADS.

Table 2 gives the estimates of the regression slopes and intercepts for the winter (January-March) and autumn (October-December) seasons, which altogether contribute more than $86 \%$ of the pairs analyzed (247 pairs). The remaining 31 pairs belong to the summer and spring and cannot be used to consider the summer and the spring relationships separately with confidence. Thus, we have estimated overall regressions for the warm period from April to September. Note that most of the boxes during this period are located south of the subpolar SST front and occur primarily in April and May. During the autumn the regression slope increases from 0.94 to 0.99 with the ARL decreasing from 27 to $10 \mathrm{~m}$. Winter values indicate slightly smaller regression slopes and larger negative and smaller positive intercepts for the uncorrected and adjusted winds, respectively. During the spring and the summer months, the slope is somewhat smaller $(6 \%-10 \%)$ than for the winter and autumn. The intercept also changes with the decreasing ARL in a larger range, which reasonably reflects the larger height correction effect for stable conditions, even after the elimination of the "very stable" cases. Although for all seasons the slope of the orthogonal regression increases slightly for the adjusted $\mathrm{R} / \mathrm{V}$ wind, the general tendency (underestimation of small winds and overestimation of strong winds) is still evident in Table 2. Quayle (1980) and Cardone et al. (1990) did not make the direct comparison for individual months or seasons, but they found remarkably different ratios between estimated and measured wind for the small, moderate, and strong winds. Cardone et al. (1990)
TABLE 2. Regression slopes and intercepts $\left(\mathrm{m} \mathrm{s}^{-1}\right)$ for the pairs of monthly mean COADS and R/V wind speed for different ARLs used for the adjustment of $\mathrm{R} / \mathrm{V}$ winds during the autumn and winter months.

\begin{tabular}{|c|c|c|c|c|c|c|}
\hline \multirow[b]{2}{*}{ ARL } & \multicolumn{2}{|c|}{$\begin{array}{l}\text { Autumn } \\
\text { (108 pairs) }\end{array}$} & \multicolumn{2}{|c|}{$\begin{array}{c}\text { Winter } \\
\text { (139 pairs) }\end{array}$} & \multicolumn{2}{|c|}{$\begin{array}{l}\text { Spring and summer } \\
\text { (31 pairs) }\end{array}$} \\
\hline & Slope & Intercept & Slope & Intercept & Slope & Intercept \\
\hline 27 & 0.939 & - & y & -0 & 9 & -0.54 \\
\hline 20 & 0.952 & -0.31 & 0.941 & -0.59 & 0.914 & -0.31 \\
\hline 15 & 0.970 & 0.14 & 0.962 & -0.13 & 0.933 & -0.07 \\
\hline 10 & 0.991 & 0.72 & 0.983 & 0.40 & 0.943 & 0.77 \\
\hline
\end{tabular}

suggested introducing the stability correction, which accounts for the thermal and moisture stratification of the near-surface air. This correction can be considered as an indirect indication of the changed from season-toseason differences between the measured and estimated winds.

\section{b. Interannual variability}

Interannual variability, and especially the long-term trends, is the key question of the reliability of COADS winds. It is rather difficult to use our collection of the $\mathrm{R} / \mathrm{V}$ measurements for the comparison with the interannual changes in the COADS winds because even in the area with very high separation of samples some months have incomplete $\mathrm{R} / \mathrm{V}$ data. Thus, we checked interannual changes for a number of months that have a high number of measurements and provide the $2^{\circ}$ monthly means for at least 9 of the 11 years available from 1981 to 1991 . We selected for our comparison the $6^{\circ} \times 8^{\circ}$ area $\left(38^{\circ}-44^{\circ} \mathrm{N}, 40^{\circ}-48^{\circ} \mathrm{W}\right)$, which provides the largest contribution of the R/V data (Fig. 2). On the basis of the computed $2^{\circ} \times 2^{\circ}$ monthly means for each individual month, the procedure of the optimal interpolation (Gulev and Kolinko 1987) has been applied to obtain the monthly means for those $2^{\circ} \times 2^{\circ}$ boxes that had incomplete measurements. Of course, even after this procedure we could not generate values for those months when there was no research vessel in the Newfoundland region. Thus, we made some changes in the COADS Release 1a wind fields to adjust them to our incomplete climatology. First, we removed from the COADS Release 1a values for those boxes and months that did not appear in our climatology of the R/V winds. In this way, we have obtained for this particular area the COADS Release 1 a version that is of the same quality (in terms of data coverage) as the $\mathrm{R} / \mathrm{V}$ dataset. Then the same procedure of optimal interpolation (Gulev and Kolinko 1987) was applied to this modified version of COADS in order to complete the missed boxes in the same manner as for the $\mathrm{R} / \mathrm{V}$ data.

Due to limited data, very careful consideration was given to the trend statistics. Linear trends were tested using Student's t-test, which additionally provided the reliability ratio (Hayashi 1982). The reliability ratio 
TABLE 3. Estimates of linear trends ( $\mathrm{m} \mathrm{s}^{-1}$ per year) in the scalar wind speed for the $\mathrm{R} / \mathrm{V}$ data, original COADS Release 1a and reinterpolated version of COADS for the winter months during 1981-91. Trends are presented for the area $38^{\circ}-44^{\circ} \mathrm{W}, 40^{\circ}-48^{\circ} \mathrm{N}$. Statistical significance according to a $t$ test $(t)$ and a Wilcoxon test $(w)$ is given for $95 \%$ level $(*)$ and $99 \%$ level $(* *)$, and $r$ is reliability ratio.

\begin{tabular}{|c|c|c|c|c|c|c|c|c|c|c|}
\hline \multirow[b]{2}{*}{ Month } & \multicolumn{3}{|c|}{$\mathrm{R} / \mathrm{V}$} & \multicolumn{3}{|c|}{$\begin{array}{c}\text { COADS } \\
\text { Release 1a }\end{array}$} & \multicolumn{3}{|c|}{ Reinterpolated COADS } & \multirow{2}{*}{$\begin{array}{c}\text { No. of } \\
\text { years }\end{array}$} \\
\hline & $a$ & $t / r$ & $w$ & $a$ & $t / r$ & $w$ & $a$ & $t / r$ & $w$ & \\
\hline Dec & 0.17 & $-/ 0.88$ & - & 0.25 & $* * / 1.25$ & $*$ & 0.34 & $* * / 1.65$ & $* *$ & 9 \\
\hline Jan & 0.13 & $-/ 0.66$ & - & 0.24 & $* * / 1.45$ & $*$ & 0.29 & $* / 1.36$ & $*$ & 9 \\
\hline Feb & 0.04 & $-/ 0.14$ & - & 0.17 & $* / 1.19$ & $*$ & 0.15 & $-/ 0.61$ & - & 9 \\
\hline
\end{tabular}

takes into account the confidence intervals that introduce the quantitative measure of the statistical significance of the tested hypothesis. According to Hayashi (1982), if the ratio $|R| \gg 1$, the true value is close to its estimate, and when $|R|>1$, the null hypothesis (no trend in our case) is rejected; that is, the trend is statistically significant. When $|R| \leq 1$, confidence intervals can be rather wide, even if the Student's t-test is formally satisfied for a certain percentage point, and the reliability of the trend estimate will be questionable. Finally, we also applied a Wilcoxon test (Pearson and Hartley 1976), which was successfully used for testing growing waves in the North Atlantic on the basis of a quite short time series.

Table 3 gives a comparison of the estimates of the linear trends in the original and modified COADS Release 1a winds with statistical significance according to

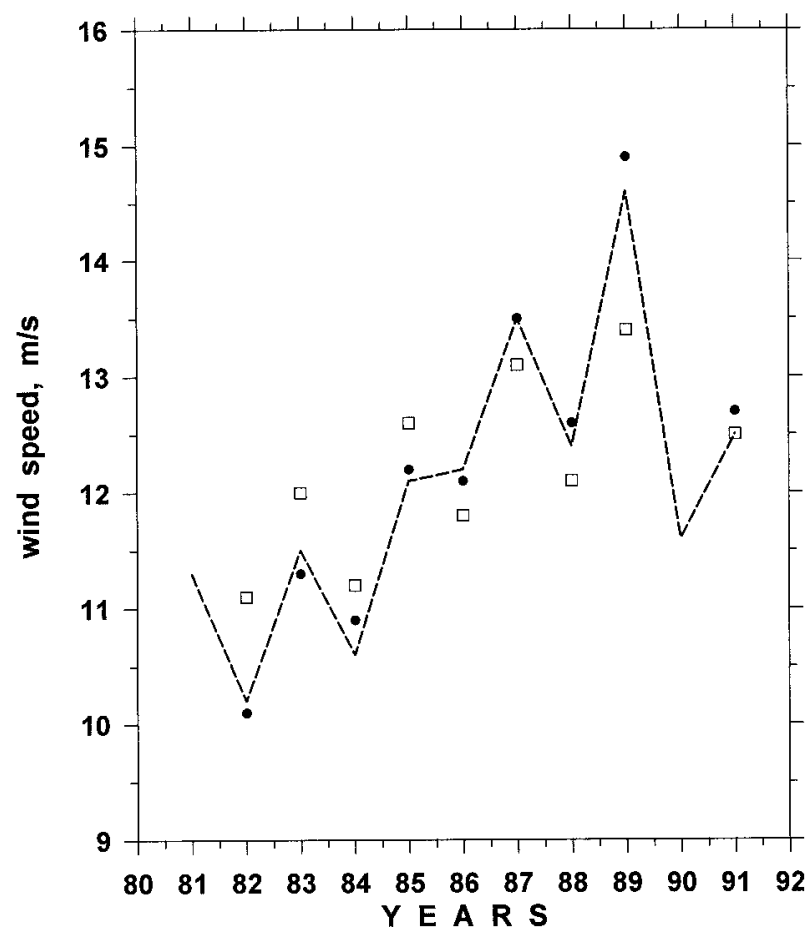

FIG. 6. Interannual variability of the original COADS Release 1a wind speed (dashed line), reinterpolated COADS wind speed (black points), and $\mathrm{R} / \mathrm{V}$ wind speed (open squares) for the area $38^{\circ}-44^{\circ} \mathrm{N}$, $40^{\circ}-48^{\circ} \mathrm{W}$ for December in the northwest Atlantic. the Student's t-test, reliability ratio, and statistical significance according to Wilcoxon test for three winter months (December-February), which are very complete with instrumental measurements. Each month provides the coverage for the 9 of 11 years. Note that the series of nine values consisted of different calendar years for every calendar month. Thus, we could not obtain, for example, winter averages for the same nine years. Figure 6 shows interannual changes in the December wind speed in the original COADS, reinterpolated COADS data, and R/V data. Remarkably for the majority of individual months within the selected box, interpolated and real values were very close to each other. Departure of the interpolated wind speed values from the original COADS Release 1a varies within the range of $0.6 \mathrm{~m}$ $\mathrm{s}^{-1}$. The mean departure is less than $0.2 \mathrm{~m} \mathrm{~s}^{-1}$. Thus, we can point out that the modified COADS climatology gives rather reliable background for the comparison with the changes in the $\mathrm{R} / \mathrm{V}$ wind speed.

COADS indicates upward wind changes in our area with significant trends for individual months from 0.3 to $2.5 \mathrm{~m} \mathrm{~s}^{-1}$ per decade. The overall averages for all months give the trend estimate of about $0.85 \mathrm{~m} \mathrm{~s}^{-1}$ per decade. This is in qualitative agreement with Diaz et al. (1995), who found a $0.3 \mathrm{~m} \mathrm{~s}^{-1}$ annual increase of the COADS winds in the North Atlantic during the 1980s. Isemer (1995) found a $0.38 \mathrm{~m} \mathrm{~s}^{-1}$ decadal increase of the COADS MSTG wind during 1946-89 in the vicinity of OWS C, located at the east of our area. A modified version of COADS mainly supports the tendencies seen in the original COADS data (Table 3), showing slightly stronger trends for December and January and a slightly weaker trend for February. Differences in the estimates result from the incompleteness of the series in the modified climatology. Thus, for January, the trends are significant at a $99 \%$ level in the original COADS and at a 95\% level in the reinterpolated COADS according to the Student t-test, although a Wilcoxon test gives 95\% significance in both series. For February, trends in the modified COADS are significant at a $90 \%$ level only, according to both the Student t-test and Wilcoxon test, and the reliability ratio is smaller than 1 . If we consider interannual changes in the scalar wind speed obtained from the R/V measurements (Table 3), there is no indication of significantly positive trends. The largest trend is in December, but it is significant only at the 
90\% level according to both the Student t-test and Wilcoxon test. Figure 6 shows differences between the estimates of positive trends in the COADS winds and the tendencies in the $\mathrm{R} / \mathrm{V}$ winds for December. Beside the trends, there is a pronounced quasi-biennial variability seen in all three time series. Alternatively, April and May values (not shown here) indicate quite pronounced downward changes of -0.4 and $-0.6 \mathrm{~m} \mathrm{~s}^{-1}$ per decade, respectively, although these estimates are obtained on the basis of only 7 years, and it is difficult to estimate their statistical significance. So, we can point out that the dramatic positive wind trends in CODAS Release 1a are not supported by the homogeneous data of research vessels, at least in the northwest Atlantic. Isemer (1995) came to the same conclusion, comparing COADS Release 1a with the data from OWS C, L, M, and $\mathrm{R}$ for the period from the mid-1970s to the late 1980s.

\section{Discussion}

The results obtained can be discussed from a number of viewpoints. On one hand, the disagreement between the COADS Release 1a and R/V winds may help to create the correct strategy of the VOS wind data processing for the evaluation of the future releases of COADS and similar climatological data. On the other hand, recommendations based on such a comparison are not free from the specific uncertainties but are linked to the features of the selected collection of R/V observations and certain geographical regions. Since the contribution of anemometer measurements increases with time, the question about the measurement height and the ship's superstructure becomes very important for the reliability of the COADS MSTG and similar products. Kent and Taylor (1997) first introduced the merging of the individual COADS reports with the WMO47 (WMO 1990) annual lists of the information about the VOS parameters including anemometer heights. Woodruff et al. (1997) reports that the WMO47 information will be attached to the COADS Release 2. At the same time, the gridded COADS Release 2 MSTG will be based on the averaging of uncorrected wind reports. Moreover, the number of the matched call signs in the COADS reports and in the $\mathrm{WMO} 47$ contributes more than $75 \%$ of the ship reports in COADS only after 1985 and is considerably smaller for the earlier years. In this context such projects as VSOP-NA (Kent and Taylor 1991; Kent et al. 1991; Kent et al. 1993) are very helpful in producing alternative datasets that could be used as an intermediate between COADS and instrumental measurements for the validation at least in limited areas and for restricted time periods.

An important problem of the reliability of anemometer measurements is the evaluation of the true wind velocity from the relative wind. This simple geometrical operation in theory must be done by officers, but in practice might be omitted, and there is no way of know-
TABLE 4. Regression slopes and intercepts $\left(\mathrm{m} \mathrm{s}^{-1}\right)$ for the pairs of monthly mean COADS and R/V zonal $\left(V_{x}\right)$ and meridional $\left(V_{y}\right)$ component of the wind speed for the original and adjusted to $15 \mathrm{~m} \mathrm{ARL}$ $\mathrm{R} / \mathrm{V}$ winds.

\begin{tabular}{cccccc}
\hline \hline $\begin{array}{c}\text { ARL } \\
(\mathrm{m})\end{array}$ & $\begin{array}{c}\text { Wind } \\
\text { com- } \\
\text { ponent }\end{array}$ & Slope & $\begin{array}{c}\text { Slope } \\
\text { variance }\end{array}$ & Intercept & $\begin{array}{c}\text { Intercept } \\
\text { variance }\end{array}$ \\
\hline 27 & $V_{x}$ & 0.875 & 0.059 & -0.39 & 0.26 \\
& $V_{y}$ & 0.936 & 0.037 & -0.24 & 0.19 \\
15 & $V_{x}$ & 0.917 & 0.054 & 0.57 & 0.22 \\
& $V_{y}$ & 0.991 & 0.038 & 0.13 & 0.19 \\
\hline
\end{tabular}

ing what percentage of the uncorrected reports contributes to the whole collection. Kent et al. (1991) argue that a better solution is to include into ship reports both true and relative wind (or only the latter one, if correction was not done). However, this will require changing the structure of coding, which is not desirable. First results from the SHIPMET questionnaire (Gulev 1996), which was distributed among nearly 300 Russian officers, showed that $19 \%$ of officers do not know about the technique of the evaluation of the true wind, $21 \%$ know but do not do it usually, 33\% do it either episodically or using the "approximate course and ship velocity," and only $27 \%$ do it correctly. The importance of the careful evaluation of the true wind depends on the relation between the major ship routes and main wind direction for certain region. For example, in our region this problem is of a high importance because major ship routes coincide in general with climatological winds. At the same time, the majority of the ships following the recommendations of meteorological services use the southern routes when traveling from Europe to the United States and cross our region only on the way back. Only ships traveling to Canada cross our area twice. Thus, we can expect that for this certain region reports with uncorrected wind (if it appears) could slightly underestimate monthly mean wind in the COADS MSTG.

We compared separately north-south and east-west components of COADS and R/V wind speed. For our region the major impact of reports with uncorrected wind is expected on the zonal component of wind. Therefore, for the meridional component, we expect better agreement between COADS and R/V measurements. Table 4 shows the regression slopes and intercepts for the $V_{x}$ and $V_{y}$ in the same manner as Table 1. Zonal wind speed indicates the larger disagreement between the COADS and instrumental measurements than the meridional component. If we consider the adjusted $\mathrm{R} / \mathrm{V}$ measurements, COADS winds overestimate the $\mathrm{R} / \mathrm{V}$ winds by nearly $0.6 \mathrm{~m} \mathrm{~s}^{-1}$, which is much higher than such an estimate for the comparison of the scalar wind (Table 1). Alternatively, the meridional component of the wind speed (Table 4) indicates better agreement between the COADS and $\mathrm{R} / \mathrm{V}$ data, giving a regression slope close to 1 for the adjusted winds. Incorrect eval- 
TABLE 5. Regression slopes and intercepts $\left(\mathrm{m} \mathrm{s}^{-1}\right)$ for the pairs of monthly mean COADS and R/V wind speed for different types of the intrabox network for the original and adjusted to 15-m ARL R/ $\mathrm{V}$ winds.

\begin{tabular}{lllllr}
\hline \hline \multirow{2}{*}{$\begin{array}{l}\text { Network } \\
\text { type for the }\end{array}$} & \multicolumn{2}{l}{ Sampled R/V wind } & & \multicolumn{2}{l}{ Adjusted R/V wind } \\
\cline { 2 - 3 } \cline { 5 - 6 } RV data & Slope & Intercept & & Slope & Intercept \\
\hline Linear I & 0.924 & -0.82 & & 0.959 & 0.08 \\
Linear II & 0.941 & -0.94 & & 0.980 & -0.09 \\
Random & 0.909 & -0.89 & & 0.943 & 0.10 \\
Clustered & 0.929 & -0.78 & & 0.957 & -0.01 \\
\hline
\end{tabular}

uation of true wind, or the drop of this evaluation, can reduce measured southwest, west, and northwest winds for our area. Winds of these directions are primarily moderate and strong. Weak winds (if they appear) usually have east and south directions and are connected with the forward part of cyclones and anticyclones. For these winds the absence of the evaluation of the true wind will alternatively systematically increase real wind. The resultant effect, seen in the Table 4 , reflects the larger contribution from the strong and moderate winds of the primarily western directions (climatological mean zonal wind varies from 3 to $5 \mathrm{~m} \mathrm{~s}^{-1}$ for this area). Thus, the obtained disagreement can partially result from the incorrect evaluation of the true wind. Some more systematic biases can result from the fact that the anemometer exposure for the astern at a number of merchant ships is characterized by fully or partially blocked flow (Kent and Taylor 1991), which can also reduce western winds that are measured on board of the ships traveling from the United States to Europe in this area.

One possible source of the disagreement obtained is the procedure of intrabox averaging. Morrissey and Maliekal (1995) found the standard errors of $2^{\circ}$ monthly mean wind speed to be strongly dependent on the intrabox network type. The R/V data are characterized by the linear network, which is aligned across the major axis of the spatial correlation function ["linear network I" in terms of Morrissey and Maliekal (1995)]. Alternatively, the COADS collection is mainly characterized by the "linear network II," that is, the data aligned along the major axis of the spatial correlation function. According to Morrissey and Maliekal (1995), linear network $\mathrm{I}$ is more credible for the intrabox averaging than linear network II and have a three to four times smaller standard error. To study the sensitivity of our comparison to the network system, we chose six $2^{\circ}$ boxes, which were very complete with instrumental measurements during February and March and provided the possibility to select different samples in order to model the two different linear networks, as well as the random and clustered networks that have the smallest and the largest standard errors, respectively (Morrissey and Maliekal 1995). Results for the selected 21 pairs are presented in Table 5. In general there is a qualitative agreement between the slopes and intercepts computed for different network types, as well as an overall winter estimate

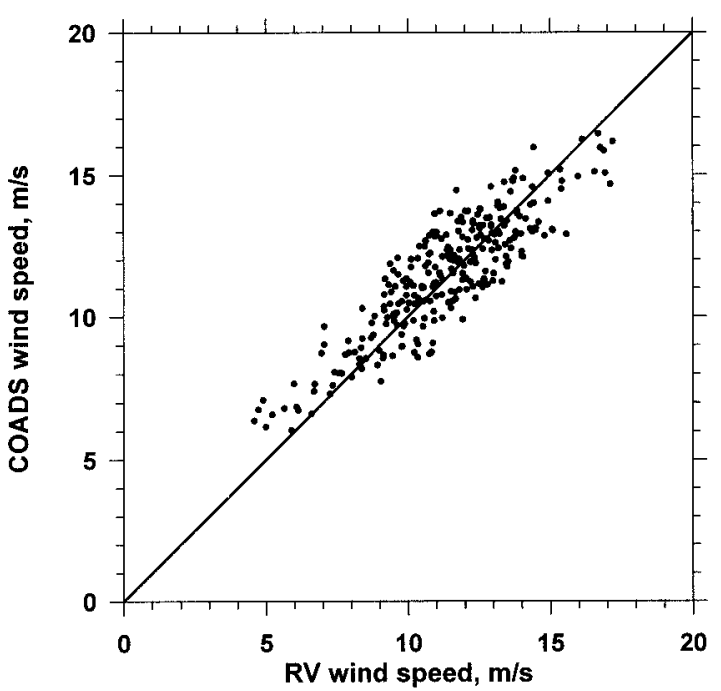

FIG. 7. Scatterplots of the monthly mean $2^{\circ} \mathrm{R} / \mathrm{V}$ and COADS wind speed after the application of the Lindau (1995) equivalent scale to the COADS visual data.

between them (Table 2). A slightly smaller bias is obtained for the clustered network and the largest is for the linear network II. Thus, we can point out that although the network arrangement of the SECTIONS data is very different from that for the COADS, results do not depend much on this difference.

Uncertainties of the conversion of the Beaufort force to the wind speed are considered as the most important source of the disagreement between estimated and measured wind. According to Kent and Taylor (1997) and many others, the old WMO code 1100 used in COADS appears to be systematically biased in relation to the real wind-underestimating low winds and overestimating high winds. Many alternative equivalent scales (Cardone 1969; WMO 1970; Kaufeld 1981; da Silva et al. 1995; Lindau 1995) were performed to remove these biases, although some of them (for example, CMM-IV) create pronounced opposite biases. Recently, Kent and Taylor (1997) made a comprehensive comparison of all known equivalent scales and found the Lindau (1995) scale and the UWM (da Silva et al. 1995) scale to be mostly unbiased compared to the others. According to our analysis, R/V measurements show smaller wind in low ranges and give higher moderate and strong winds. The disagreement obtained cannot be reduced by the conversion of visual winds to any other equivalent scale. All known scales when applied will only make the tendency obtained more pronounced (Kent and Taylor 1997).

To test the effect of the application of the other scales, we selected in the COADS LMR for 1981-91 all visual estimates using a COADS wind indicator flag. Then the data were converted into the Lindau (1995) scale, and the $2^{\circ} \times 2^{\circ}$ climatology was obtained by using these converted visual estimates and anemometer measurements. Figure 7 shows the scatterplot of the monthly 
TABLE 6. Regression slopes and intercepts $\left(\mathrm{m} \mathrm{s}^{-1}\right)$ for the pairs of monthly mean COADS visual and anemometer winds and the R/V wind speed.

\begin{tabular}{lccrc}
\hline \hline $\begin{array}{c}\text { Type of the } \\
\text { COADS data }\end{array}$ & Slope & $\begin{array}{c}\text { Slope } \\
\text { variance }\end{array}$ & $\begin{array}{c}\text { Intercept } \\
\text { Intercept }\end{array}$ & variance \\
\hline Anemometer & & & & \\
$\quad$ measurements & 0.849 & 0.078 & 0.75 & 0.29 \\
Visual (WMO 1100) & 1.033 & 0.046 & -0.48 & 0.23 \\
Visual (Lindau 1995) & 0.941 & 0.043 & 0.06 & 0.24 \\
\hline
\end{tabular}

mean $\mathrm{R} / \mathrm{V}$ and COADS winds, based on the Lindau (1995) scale and anemometer measurements. Since the Lindau (1995) scale was performed for the 25-m ARL, which is also assumed to be the reliable estimate of the height of anemometer measurements in this area (section $3 \mathrm{a}$ ), all $\mathrm{R} / \mathrm{V}$ measurements were adjusted to this height. The regression slope is 0.88 and the intercept is 0.21 . Thus, the mean bias is slightly higher than that obtained for the WMO 1100 scale for the ARL $=15$ $\mathrm{m}$, and there is pronounced overestimation of the $\mathrm{R} / \mathrm{V}$ winds in low ranges and underestimation in the high ranges. Then we have compared separately COADS climatology based on the anemometer measurements and on the visual estimates. We selected among 278 pairs of boxes, 104 pairs that contain both anemometer and visual estimates and both provide equal intramonthly variances when compared to the $\mathrm{R} / \mathrm{V}$ data variance $\left(\chi^{2}\right.$ test, $95 \%$ significance). For comparison of the anemometer climatology, all SECTIONS data were excluded from the COADS LMR and the R/V data were adjusted to $25 \mathrm{~m}$ ARL. For the comparison with visual estimates, the adjustment was done to 10 and to $25 \mathrm{~m}$, respectively, for WMO 1100 and Lindau (1995) scales. Results are presented in Table 6. Although the Lindau (1995) scale gives the least bias among the three pairs of comparisons, the regression slope indicates that there is still a quite pronounced overestimation of small winds and underestimation of strong winds. The WMO 1100 scale gives overall underestimation of winds, although it is smaller than those given by Kent and Taylor (1997) and Quayle (1980), which can partially result from the lesser contribution of really small winds that are especially biased in the WMO 1100 scale. At the same time, the WMO 1100 scale gives the closest to unity regression slope. The largest bias and the slope departure from unity gives the comparison with anemometer winds.

\section{Conclusions}

We undertook regional comparison of the COADS winds with independent instrumental observations. Nevertheless, this comparison (as practically any comparison of this kind) is influenced by the presence of the partial $\mathrm{R} / \mathrm{V}$ data in both datasets. Taking into account that over the years more and more historical data will be incorporated into the COADS, it is of great importance to provide the capability to identify certain da- tasets within COADS using ship call signs and desk source code.

We found overestimation of the COADS winds in the low ranges and underestimation in the high ranges. Differences between daytime and nighttime values were found to be small and insignificant. The application of different Beaufort scales also cannot change this tendency. Thus, the main sources of disagreement between the $\mathrm{R} / \mathrm{V}$ and the COADS monthly mean wind appear to be the anemometer measurements in COADS. Kent et al. (1993) argued that the number of uncertainties in anemometer measurements is not less than in Beaufort reports and is even higher for hand-held anemometers. In this context, the incorporation of the WMO47 information into the COADS collection (Kent and Taylor 1997 ) is of a high importance, and it is very desirable that the COADS Release 2 MSTG would also be performed with this valuable information taken into account. At the same time, availability of individual COADS observations (LMR), necessarily supplied with permanently updated metadata, will be important for the understanding and correction of the wind inhomogeneities in COADS.

The results obtained show that for our particular region, when the routes are different for the ships traveling to and from America, the disagreement primarily results from the incorrect (or omitted) evaluation of the true wind by the officers, which can be identified by the separate comparisons of the zonal and meridional components of wind. Considerable efforts are needed to quantify the impact of this uncertainty. The demand to report both true and relative wind is reasonable, but it can (even if satisfied) improve only new contributions into the COADS. For historical data, questionnaires such as SHIPMET can partially help, if we believe that the officers report the reality rather than what the questionnaire expects from them (i.e., to cite the instructions). Random errors in the percentages of these questionnaires are from $4 \%$ to $10 \%$. Thus, the conclusions based on these percentages should be considered more qualitative than quantitative.

An important problem is the reliability of the dramatic increase of COADS scalar wind during late 1970s and 1980 s, which is not supported in general by the consideration of R/V measurements. Diaz et al. (1995) report that the contribution of anemometer measurements has increased for the whole ocean from $43 \%$ to $49 \%$. For our area this tendency is even more pronounced due to the local impact of our R/V data, $25 \%$ of which were included into the COADS collection. Another regional source of observed trends can be connected with the incorporation into the COADS of measurements from Canadian oil platforms, which have remarkably high ARL and appeared during the last two decades. The question about the reliability of COADS wind trends during late 1970s and 1980s is still open. Comparisons with spatially distributed homogeneous instrumental data (this study), with instrumental measurements in 
fixed positions, upper-air wind observations (Isemer 1994, 1995), and comparisons with pressure gradients and geostrophic wind hindcast (Ward 1992) indicate either significantly smaller trends or do not show any pronounced trends at all. However, the trend estimates are based on a quite short time series and should be always be considered in a view of 1) their statistical significance and 2) longer-scale climate variability, which may contain the observed trendlike changes as parts of, say, decadal and interdecadal variations.

A number of conclusions obtained cannot be directly applied to the other areas of the ocean. This area has quite specific stratification conditions and is characterized by the stable stratification during a considerable part of the year. The location of the main ship routes that are primarily those directed to the east is also quite specific. Moreover, different regions are characterized by different ratios of numbers of anemometer measurements to the total number of reports, different contributions from different nations, and very different climatology of wind statistics. Nevertheless, in some similar areas, such as a Kuroshio region, our results can help to evaluate biases in the monthly wind speed.

Acknowledgments. This study has been partially done during my work at IFM (Kiel) in 1993 and 1994. I greatly appreciate the support of Prof. Lutz Hasse. Thanks to Hans-Joerg Isemer of GKSS (Geesthacht) and Alexey Arkhipkin of IORAS (Moscow) for very productive discussions. COADS data were made available by courtesy of Steve Worley of NCAR (Boulder). I appreciate the helpful discussions during the International COADS Winds Workshop (Kiel 1994), which was organized by Henry Diaz of ERL-NOAA (Boulder) and Hans-Joerg Isemer. Suggestions and criticism of three anonymous reviewers are greatly appreciated. This study is supported by Deutsche Forschugsgemeinscaft, Sonderforschungsbereich SFB 133 and the Ministry of Science and Technology of Russia.

\section{REFERENCES}

Bigg, G. R., 1993: Comparison of coastal wind and pressure trends over the tropical Atlantic: 1946-1987. Int. J. Climatol., 13, 411421.

Blanc, T. V., 1986: The effect of inaccuracies in weather ship data on bulk-derived estimates of flux, stability, and sea-surface roughness. J. Atmos. Oceanic Technol., 3, 12-26.

Cardone, J. S., J. G. Greenwood, and M. A. Cane, 1990: On trends in historical marine wind data. J. Climate, 3, 113-127.

Cardone, V., 1969: Specification of the wind distribution in the marine boundary layer for wave forecasting. New York University, Rep. TR69-1, 131 pp. [Available from Ocean Weather, Inc., Cos Cob, CT 06807.]

da Silva, A. M., C. C. Young, and S. Levitus, 1994: Atlas of Surface Marine Data 1994. Vol. 2. National Oceanic and Atmospheric Administration, $419 \mathrm{pp}$.

,-- , and - , 1995: Toward a revised Beaufort equivalent scale. Proc. Int. COADS Winds Workshop, Kiel, Germany, NOAA, 270-286.

Diaz, H. F., X. Quan, and C. Fu, 1995: Marine surface wind changes during 1978-1992: An estimation based on COADS. Proc. Int. COADS Winds Workshop, Kiel, Germany, NOAA, 48-67.

Dobson, F. W., 1981: Review of reference height for an averaging time of surface wind measurements at sea. WMO Commission on Marine Meteorology and Related Oceanographic Activities Rep. 3, 64 pp.

Gulev, S. K., 1994: Influence of space-time averaging on the oceanatmosphere exchange estimates in the North Atlantic midlatitudes. J. Phys. Oceanogr., 24, 1236-1255.

_ 1995: Long-term variability of sea-air heat transfer in the North Atlantic Ocean. Int. J. Climatol., 15, 825-852.

— , 1996: SHIPMET_-Pilot questionnaire for VOF officers. Release 1. Internal Note, P. Shirshov Institute of Oceanology, Moscow, Russia, 43 pp. [Available from P. Shirshov Inst. of Oceanology, 117218, Moscow, Russia.]

— rological data from the oceanic energy active regions. Meteor. Hydrol., 12, 54-61.

Hasse, L., M. Grunewald, J. Wucknitz, M. Dunkel, and D. Schriever, 1978: Profite-derived turbulent fluxes in the surface layer under disturbed and undisturbed conditions during GATE. "Meteor" Forschungsergeb., 13B, 24-40.

Hayashi, Y., 1982: Confidence intervals of a climatic signal. J. Atmos. Sci., 39, 1895-1905.

Isemer, H.-J., 1994: On the homogeneity of surface wind speed records from ocean weather stations. Tech. Report, Institute für Meereskunde, Kiel, Germany, 81 pp. [Available from Institut für Meereskunde, Kiel, D-24105 Germany.]

_ 1995: Trends in marine surface wind speed: Ocean weather stations versus voluntary observing ships. Proc. Int. COADS Winds Workshop, Kiel, Germany, NOAA, 68-84.

_- and L. Hasse, 1991: The scientific Beaufort equivalent scale: Effects on wind statistics and climatological air-sea flux estimates in the North Atlantic Ocean. J. Climate, 4, 819-836.

Kahma, K. K., and M. Lepparanta, 1981: On errors in wind speed observations on R/V Aranda. Geophysica, 17, 155-165.

Kaufeld, L., 1981: The development of a new Beaufort equivalent scale. Meteor. Rundsch., 34, 17-23.

Kent, E. C., and P. K. Taylor, 1991: Ship observing marine climate: A catalogue of the voluntary observing ships participating in the VSOP-NA. WMO Tech. Document 456, WMO, Geneva, Switzerland, $123 \mathrm{pp}$.

- , and - 1997: Choice of a Beaufort Equivalent Scale. J. Atmos. Oceanic Technol., 14, 228-242.

— B. S. Truscott, P. K. Taylor, and J. S. Hopkins, 1991: The accuracy of ship's meteorological observations. Results of the VSOP-NA. WMO Tech. Document 455, WMO, Geneva, Switzerland, $86 \mathrm{pp}$.

— - P. K. Taylor, B. S. Truscott, and J. S. Hopkins, 1993: The accuracy of voluntary observing ships' meteorological observations-Results of the VSOP-NA. J. Atmos. Oceanic Technol., 10, 591-608.

Large, W. G., and S. Pond, 1981: Open ocean momentum flux measurements in moderate to strong winds. J. Phys. Oceanogr., 11, 324-336.

Legler, D., 1991: Errors in five-day mean surface wind and temperature conditions due to inadequate sampling. J. Atmos. Oceanic Technol., 8, 705-712.

Lindau, R., 1995: A new Beaufort equivalent scale. Proc. Int. COADS Winds Workshop, Kiel, Germany, NOAA, 232-252.

_ calibration of historical wind observations at sea. Trop. OceanAtmos. Newsl., 54, 7-12.

Liu, W. T., K. B. Katsaros, and J. A. Businger, 1979: Bulk parameterization of air-sea exchanges of heat and water vapor including the molecular constraints at the interface. J. Atmos. Sci., 36, 1722-1735.

Morrissey, M. L., and J. A. Maliekal, 1995: Standard error estimation of COADS monthly mean winds. Proc. Int. COADS Winds Workshop, Kiel, Germany, NOAA, 165-170. 
Pearson, E. S., and H. O. Hartley, Eds., 1976: Biometrika Tables for Statisticians. Vol. 2. Biometrica Trust, $226 \mathrm{pp}$.

Peterson, E. W., and L. Hasse, 1987: Did the Beaufort scale or the wind climate change? J. Phys. Oceanogr., 17, 1071-1074.

Quayle, R. G., 1980: Climatic comparisons of estimated and measured winds from ships. J. Appl. Meteor., 19, 142-156.

Ramage, C. S., 1984: Can shipboard measurements reveal secular changes in tropical air-sea heat flux? J. Climate Appl. Meteor., 23, 187-193.

Slutz, R. J., S. J. Lubker, J. D. Hiscox, S. D. Woodroof, R. L. Jenne, D. H. Joseph, P. M. Steurer, and J. D. Elms, 1985: Comprehensive Ocean-Atmosphere Data Set: Release 1. 268 pp.

Ward, M. N., 1992: Provisionally corrected surface wind data, worldwide ocean-atmosphere surface fields, and Sahelian rainfall variability. J. Climate, 5, 454-475.

— Ocean 1949-1988. J. Climate, 9, 1877-1895.

Weare, B. C., and P. T. Strub, 1981: The significance of sampling biases on calculated monthly mean oceanic surface heat fluxes. Tellus, 33, 211-224.

WMO, 1970: The Beaufort scale of wind force. Reports on marine science affairs, Rep. 3, World Meteorological Organization, Geneva, Switzerland, $22 \mathrm{pp}$.

_ 1973: Commission for marine meteorology. Abridged Final Report of the Sixth Session, World Meteorological Organization, Geneva, Switzerland, 117 pp.

, 1990: International list of selected, supplementary and auxiliary ships. WMO-47, World Meteorological Organization, Geneva, Switzerland.

Woodruff, S. D., S. J. Lubker, K. Wolter, S. J. Worley, and J. D. Elms, 1993: Comprehensive Ocean-Atmosphere Data Set (COADS). Release 1a: 1980-92. Earth Syst. Monitor, 4, 1-8.

, H. F. Diaz, J. D. Elms, and S. J. Worley, 1998: COADS Release 2 data and metadata enhancements for improvements of marine surface flux fields. Phys. Chem. Earth, in press.

Wu, Z., and K. Li, 1995: Wind speed discontinuity related to Beaufort wind observations and its influence on latent heat flux. Proc. Int. COADS Winds Workshop, Kiel, Germany, NOAA, 212-231. 